\title{
Vaccines' Safety and Effectiveness in the Midst of Covid-19 Mutations
}

\author{
Xanya Sofra ${ }^{1,2}$ (1) \\ ${ }^{1}$ City University, London, UK \\ ${ }^{2}$ New School for Social Research, New York, USA \\ Email: science@iellios.com
}

How to cite this paper: Sofra, X. (2021) Vaccines' Safety and Effectiveness in the Midst of Covid-19 Mutations. Health, 13, 283-298.

https://doi.org/10.4236/health.2021.133023

Received: February 6, 2021

Accepted: March 15, 2021

Published: March 18, 2021

Copyright (c) 2021 by author(s) and Scientific Research Publishing Inc. This work is licensed under the Creative Commons Attribution International License (CC BY 4.0).

http://creativecommons.org/licenses/by/4.0/

\begin{abstract}
We examined the coronavirus classification and evolution through its multiple mutations that have increased its transmissibility rate up to $70 \%$ globally, threatening to undermine the promise of a number of emerging vaccines that primarily focus on the immune detection of the Spike trimer. The safety and effectiveness of different vaccination methods are evaluated and compared, including the mRNA version, the Adenovirus DNA, Spike protein subunits, the deactivated virus genres, and the live attenuated coronavirus. Mutations have been long considered as random events, or mistakes during the viral RNA replication. Usually, what can go wrong will go wrong; therefore, repeated transformations lead to the extinction of a virus. On the contrary, the aggregate result of over 300,000 Covid-19 variants has expanded its transmissibility and infectiousness. Covid-19 mutations do not degrade the virus; they empower and facilitate its disguise to evade detection. Unlike other coronaviruses, Covid-19 amino acid switches do not reflect the random unfolding of errors that eventually eradicate the virus. Covid-19 appears to use mutations adaptively in the service of its survival and expansion. We cite evidence that Covid-19 inhibits the interferon type I production, compromising adaptive immunity from recognizing the virus. The deleterious consequences of the cytokine storm where the $\mathrm{CD} 8^{+}$killer cells injure the vital organs of the host may well be a Covid-19 manoeuvring to escape exposure. It is probable that evolution has programmed Covid-19 with an adeptness designed to debilitate key systemic defences to secure its subsistence. To date the infectiousness of the Covid-19 pandemic is exponentially increasing, denoting the possibility of an even more dangerously elusive, inconspicuous, and sophisticated version of the disease.
\end{abstract}

\section{Keywords}

SARS-CoV2, Covid-19, mRNA Vaccines, DNA Vaccines, Inactivated Virus 
Vaccines, Covid-19 Mutations, D614G, B117, P1, 501Y.V2, Immune Memory, Spike Protein

\section{Coronavirus Evolution}

The corona virus is a positive RNA virus enveloped by a membrane that was first identified in Wuhan in 2019 (SARS-CoV2 or Covid-19). It is classified under the beta coronaviruses category along with SARS-CoV (Severe Acute Respiratory Syndrome) and MERS CoV (Middle East Respiratory Syndrome). There are other beta type of human coronaviruses that cause enteric and upper respiratory tract infections, experienced during the common cold, such as the HCoV-OC43 and HCoV-HKU1. On the other hand, HCov-229D and HCoV-NL63 come under the alpha classification. Feline (FCoVs) and canine corona viruses (CCoVs) are also sorted under the alpha group. The remaining coronaviruses fall under the genera of gamma and delta categories that primarily affect poultry, wildlife and other birds, although rather sparce information is available regarding the delta division [1] [2]. Very different types of viruses, such as the Bafinivirus infects fish, while the Aterivirus is isolated in specific species including mice, monkeys, horses and pigs [3].

The highly contagious Covid-19 pandemic, resulting in 99,434,832 cases and $2,132,373$ deaths globally by January 2021 , has been one of the primary focuses of scientific research and review. Unlike the MERS-CoV that uses adenosine deaminase complexing protein 2, also known as Dipeptidyl peptidase-4 (CD26), as its primary receptor, both SARS-CoV and Covid-19 (SARS-CoV2) target and fuse with the angiotensin-converting enzyme 2 (ACE2) that serves as the viral portal into the cell. During their multiplication process, all viruses evolve to outlive the immune counterattack. Interestingly, these mutations appear to enhance the effectiveness and transmissibility of Covid-19, in contrast to other types of coronaviruses which are adversely affected by repeated mutations, eventually becoming extinct.

\section{Coronavirus Composition}

The genome of corona viruses is composed by sequences of around 26,000-32,000 variations of the Ribonucleic Acid (RNA) nitrogenous bases: adenosine, cytosine, guanine, and uracil. It harbours 6 - 11 Open Reading Frames (ORFs), 67\% of which encode 16 non-structural proteins (nsps) that direct virus assembly, transcription and replication in connection with the host, and the rest encode the accessory and structural proteins. Structural proteins include the main surface trimeric Spike glycoprotein (S) that binds and fuses with the ACE2 receptor, a key to lock process that releases the viral RNA into the cells; the smaller surface Envelope (E) protein, the Membrane (M), and the Nucleocapsid (N) viral protein that defensively surrounds the genome. The $\mathrm{N}$ protein offers protection 
and signature sequences, equipping the virus with adaptation skills that enable it to survive the adversities of the host's environment. The immune defence assembled against the antigen is composed by: A/ antibodies (innate immune system) that prophylactically cover the ACE2 receptor to obstruct the Spike's contact and fusion with the human cells; and $\mathrm{B} /$ the adaptive immune response comprised by a number of cells including cytotoxic T-killer cells or $\mathrm{CD} 8^{+}$that clasp onto the infected cells' antigens, and obliterate them by releasing perforin and granzyme that is absorbed through the cellular pores [4] [5].

\section{The Kinship between SARS-CoV and Covid-19}

The SARS-CoV and Covid-19 genomes are similar, however, there are important differences that may hinder upon the Covid-19 rate of infectiousness and virulence. Covid-19 is missing the 8 a accessory protein that is present in SARS-CoV. The Covid-19 8b accessory protein has 37 more amino acids than SARS-CoV; and the SARS-CoV 3b has 132 more amino acids than Covid-19. Overall, SARS-CoV and Covid-19 have significant structural differences that amount to 380 amino acid substitutions; for example, the non-structural nsp3 protein has 102 variations in its amino acid sequence, the nsp2 has 61 amino acid conversions, and the Covid-19 Spike protein has 27 different amino acids than SARS-CoV [6] [7]. Therefore, despite their kinship, the two viral configurations, SARS-CoV and Covid-19 are packed with different messages that are bound to have important implications pertaining to their pathogenetic effects.

The $S$ gene that encodes the Spike protein in Covid- 19 is approximately $24 \%$ different from the $\mathrm{S}$ gene in SARS-CoV, and $65 \%$ different from the $\mathrm{S}$ gene in MERS-CoV. The $\mathrm{N}$ gene that encodes the nucleocapsid protein has around $90 \%$ homology between SARS-CoV and Covid-19, but only 48\% between MERS-CoV and Covid-19. The E and M proteins' genes of Covid-19 have a $94 \%$ and $90 \%$ similarity with the SARS-CoV E and M genes respectively. Moreover, a comparison between Covid-19 and SARS-CoV has unveiled significant differences between the open reading frames ORF3a, ORF6, and ORF8, with homology rates of only $72 \%, 68 \%$, and $40 \%$ respectively. The ORF7a appears to have the highest similarity rate, approaching $85 \%$ [8] [9] [10].

The trimeric Spike (S) protein undergoes a structural transformation while binding with the ACE2 receptor. As a result, the S1 subunit sheds, allowing the S2 subunit to fuse with the receptor. This process is common in both SARS-CoV and Covid-19. The structural transformation of the S1 subunit consists of two conformation states, the up that exposes and makes the viral receptor available and the down that closes off the receptor. However, in SARS-CoV the down conformation of the receptor binding domain clicks into the N-terminal domain of the trimeric Spike (S) protein, while in the Covid-19, the down receptor fits into the central cavity of the trimer [11] [12]. This may be of significance under the assumption that the $\mathrm{N}$-terminal domain remains available, in light of recent findings that certain human antibodies bind with the N-Terminal Domain (NTD). 
NTD targeting human antibodies can be added to those binding with the Receptor Binding Domain (RBD) for greater therapeutic efficiency [13] [14].

\section{Covid-19 Neutralizing Antibodies}

Covid-19 neutralizing antibodies are $\mathrm{Y}$ shaped proteins that can recognize the S1 $\mathrm{RBD}$ and fit into the viral antigens like a key to a lock. This prohibits the virus from binding with the ACE2 cellular receptor, thus preventing viral entry. Other antibodies can neutralize the Heptad Repeat 2 (HR2) domain to impede S2 fusion with the ACE2 receptor, so even if the Spike protein can bind with the ACE2 receptor, the second step of antigen/receptor fusion is compromised, disallowing Covid-19 entry into the cells, without which the virus can neither replicate, nor spread inside the body [15].

A recent study experimented on a powerful monoclonal antibody, LY-CoV555, that binds with the Covid-19 spike protein obstructing it from fusing with the cells' ACE2 receptors. The results of 309 patients who received the LY-CoV555 antibody treatment were compared to 148 patients who received placebo. Eighty percent of all 452 participating patients had mild Covid-19 symptomatology. By the $11^{\text {th }}$ day of clinical observation both experimental and placebo group had a significantly reduced viral load, with the treated patients exhibiting a modest advantage. The experimental group patients who received a $2800 \mathrm{mg}$ antibody dose had a -0.53 difference from the placebo group $(\mathrm{p}=0.02 / \mathrm{p}<0.05)$, which is a statistically significant result. Neither a lower dose of $700 \mathrm{mgs}(\mathrm{p}=0.38)$ nor a higher dose of $7000 \mathrm{mgs}(\mathrm{p}=0.7)$ were statistically significant. Importantly, however, when the rate of hospitalizations was examined on the $29^{\text {th }}$ day, the percentage of the viral load in the experimental group that was treated with LY-CoV555, was $1.6 \%$, contrasted with the significantly higher viral load of the placebo/control group that was $6.3 \%$. Further analysis focusing on high risk aged $(>65)$ and obese $(\mathrm{BMI}>35)$ individuals denoted a diminished hospitalization rate of $4.2 \%$ for those receiving LY-CoV555, when compared to $14.6 \%$ of non-treated patients [16].

\section{Immune Memory}

Immune memory that develops from milder forms of coronaviruses such as the HCoV variants (229E, NL63, OC43, HKU1) which cause the common cold, may be a significant factor contributing in the activation of immune defences to obstruct the virus, and/or reduce the viral load that diminishes contagion [17] [18]. Immune memory pertains to antibodies that are secreted by B cells, the adaptive immune system killer-T cells $\left(\mathrm{CD}^{+}\right)$that obliterate infected cells, and helper $\mathrm{T}$ cells $\left(\mathrm{CD}^{+}\right)$that are in charge of activating cytokines. Unfortunately, recent studies have shown that individuals infected with milder forms of coronavirus related to the common cold do not develop neutralizing antibodies that can be useful in Covid-19 [19]. However, the cytotoxic $\mathrm{CD}^{+} \mathrm{T}$ cells have indicated a longer lasting SARS-CoV viral recognition, as illustrated by research evidencing 
that $\mathrm{CD}^{+} \mathrm{T}$ cells were reminiscent in $60.9 \%$ of SARS-CoV recovered patients for at least six years, whereas these patients' B cells specific memory, that is crucial in generating antibodies, appeared to be negligible or absent [20]. Obviously, the longer lasting the immune memory, the superior the immune intelligence. This is the purpose of vaccination: to enhance inherent immune memory by presenting the Spike protein that informs the immune system of the malevolence of the enemy, thus prohibiting future binding and fusion between the trimer and the ACE2 receptors. This type of innate immune "education," designed to obstruct viral entry altogether, is particularly useful in the elderly, whose adaptive immune response is compromised due to aging, and who will be inherently more vulnerable in combating the antigen via the adaptive immune defences, once Covid-19 has invaded human cells and has started multiplying [21].

\section{Robust CD4+ T and CD8+ T Cells Memory}

A recent study has identified $\mathrm{CD} 4^{+} \mathrm{T}$ cells which appeared to be reactive to Covid-19 Spike (S) glycoprotein of $83 \%$ of Covid-19 patients, targeting epitomes in both the $\mathrm{N}$ and $\mathrm{C}$ terminals of $\mathrm{S}$, as well as in $34 \%$ of healthy controls, despite the fact that the target was limited to the $\mathrm{C}$ terminal. These investigators entertained the possibility that the $\mathrm{CD} 4^{+} \mathrm{T}$ cells found in healthy controls that were reactive to Covid-19 S protein, may be the result of previous exposure to the common cold variant virus under the $\mathrm{HCoV}$ umbrella [22]. Another recent study revealed that Covid- 19 patients have $70 \%$ of reactive $\mathrm{CD} 8^{+}$cytotoxic cells and $100 \%$ of $\mathrm{CD}^{+}$helper cells, which appeared to recognize the Spike, Membrane and Nucleocaspid proteins, as well as certain non-structural proteins (nsp3, nsp4) and open reading frames (ORF3a and ORF8). Additionally, they identified $50 \%$ of $\mathrm{CD}^{+} \mathrm{T}$ helper cells and $20 \%$ of $\mathrm{CD}^{+} \mathrm{T}$ cytotoxic cells reacting to the Spike, Membrane, and non-structural proteins in individuals that had tested negative to Covid-19, again suggesting that these cytotoxic and helper T cells' reactivity was obtained from previous exposures to milder coronavirus forms such as HCoV-OC43 and HCoVNL63 which, as previously noted, are responsible for the "common cold." The $\mathrm{CD} 4^{+}$and $\mathrm{CD} 8^{+}$cells' reactivity to open reading frames (ORFs) is significant, considering that ORFs encode both non-structural and structural proteins as well as assembly ones [23].

The immune memory of $\mathrm{CD} 4^{+}$and $\mathrm{CD} 8^{+} \mathrm{T}$ cells is an encouraging finding. However, allowing Covid-19 to enter the system which will occur in the absence of antibodies, may be already too late, especially in elderly, or immunosuppressed individuals. The optimum method of fighting Covid-19 is focusing on antibodies that can block viral invasion in the first place. This is important for two reasons: Preventing viral entry into the cells is the safest option. Once Covid19 enters the cells, the $\mathrm{CD} 8^{+}$cells must exterminate the infected cells, a necessary intervention, but a casualty nevertheless, that can often injure the host. Additionally, there is evidence that coronavirus inhibits the interferon type I production and therefore, it suppresses the ability of the adaptive immune sys- 
tem to recognize the virus, possibly leading to the destruction of healthy cells. This is illustrated by the cytokine storm that indiscriminately attacks and rampages the host's vital organs [24] [25] [26]. What seems to happen during the cytokine storm is that the adaptive immune system is informed about the lethal danger, but has difficulty identifying the enemy that is evasive and imperceptible due to insufficient availability of Interferon I. As a result, immune counterattack is persistently fierce yet, undifferentiating, with deleterious consequences for the human body. The inhibition of the interferon type I production that compromises adaptive efficiency can be particularly detrimental to aged individuals with compromised immunity, who are faced by viral influx, and rely on the adaptive immune system for protection. This is why neutralizing antibody treatments have become so promising in the treatment of older Covid-19 patients.

\section{Vaccines}

Covid-19 messenger Ribonucleic Acid (mRNA) based vaccines, like the twodose Pfizer/BioNTech and Moderna vaccines, that have now received emergency use authorization from the FDA, are developed by first sequencing the gene of the $S$ protein, followed by a transcription of its $\mathrm{mRNA}$, and finally encapsulating the nucleotide-modified messenger in a lipid nanoparticle that is subsequently delivered within a sterile saline solution, acting as a dilutant, into the muscles of the host's upper arm. mRNA is a single stranded molecular sequence that can be read by the host's ribosomes. The intention is to introduce the immune system to the configuration of the Spike protein, provoking it to produce the specific antibodies that can defensively wrap around the Spike protein to prohibit viral binding, fusion and entry into the human cells [27]. The Moderna vaccine encodes the Covid-19 S1 subunit of the trimer that binds with the ACE2 receptors, as well as the $\mathrm{S} 2$ one that fuses with the ACE2 receptors, releasing the viral RNA into the cells. For additional safety, the S2 subunit is stabilized by substituting two amino acids at two consecutive positions, 986 and 987, by prolines which are secondary amines that do not contain the amino-group $\mathrm{NH}$, often used in the biosynthesis of proteins.

The vaccine's effect on children, pregnant women and individuals with specific pre-existing conditions is currently unclear, since the above mentioned populations were excluded from the clinical studies. Additional unknowns involve the vaccine's interaction with a wide range of medications; the durability of immune protection against viral infection; and the vaccine efficiency against new viral mutations [28].

Two other vaccines are produced by inserting the Adenovirus' DNA which also contains an $\mathrm{S}$ protein, after deleting part of its genetic sequence, hence rendering it unable to replicate. The AstraZeneca vaccine uses the Adenovirus found in chimpanzees, while the Johnson and Johnson vaccine uses an Adenovirus derived from humans. Other vaccine research companies like the Novavax and Sanofi-GlaxoSmithKline produce the spike protein vaccines in insect cells 
out of recombinant baculovirus [29]. Protein subunit vaccines utilise an isolated protein, in this case the Spike protein, which is purified from any viral infectious components to establish safety, and provide immunocompromised individuals with the best alternative. The problem arises when the isolated protein becomes denatured, losing its quaternary, tertiary or secondary structure as well as its functionality, thus failing to stimulate the immune production of the necessary antibodies that can ultimately protect the system against Covid-19. Therefore, its high safety may be undermined by its potentially compromised efficiency [30].

An alternative method is vaccination with a Covid-19 virus that has been deactivated and therefore, it is unable to reproduce. This type of vaccine research has obtained different Covid-19 strains from hospitalized patients around the world including China, Italy, Switzerland, United Kingdom and Spain, and has chemically inactivated the hazardous viral features, leaving a purified, disarmed Covid-19 version that can no longer assail the body. Introducing the sight of the inactivated virus in terms of the new PiCoVacc prepares the body to anticipate future viral invasion and encompass immune defences by eliciting potent antibodies, which have so far demonstrated an ability to neutralize at least 10 viral mutations in mice, rats and nonhuman primates. The PiCoVacc was formed by deactivating the CN2 strain and testing it against CN3, CN5 and OS6, as well as the $\mathrm{CN} 1$ and OS1, which are closely related to the Covid-19 mutations observed in Wuhan that evinced severe clinical symptoms. These investigators report that the purified inactivated virus exhibited genetic stability, despite multiple passages. The comparison of the different purification stages unveiled minor amino acid substitutions in the Envelope protein-residue 32, which replaced Alanine (A) with Aspartate (D). It also presented an interchange between Threonine (T) with Isoleucine (I) in the non-structural protein nsp10-residue 49. Genetic stability persisting despite inactivation, signifies that the immune system should be able to recognize and create antibodies to potentially protect the cells from future mutations. Immune recognition should occur despite future alternations of the Spike protein, designed to disguise it, so that it eludes antibodies, inconspicuously succeeding in infecting the cells [31] [32].

\section{Vaccines' Comparison}

Theoretically, the protein subunit, as well as the RNA/DNA vaccines appear to demonstrate both safety and effectiveness. The Spike mRNA can only express the S protein, which is only one out of around 29 primary proteins that compose Covid-19, thus making it impossible for the virus to replicate. The DNA vaccine is not even based on the Covid-19 virus and its genetic sequence is altered to disable reproduction within the cell. As a result of the vaccination, the $\mathrm{B}$ cells can produce antibodies for the particular $S$ protein configuration presented, thus obstructing the Covid-19 spike protein from targeting and fusing with human cells. However, any formation of immune memory resulting from this process can be rendered ineffective by a viral mutation that substantially disguises the $S$ 
protein to be unrecognizable by the immune system. On the other hand, the genetic stability of inactivated vaccines could perhaps offer protection against several mutated strains; however, it is unclear whether accurately examining and mapping certain current strains can extend to future emerging ones. Additionally, it is unclear how many vaccine dosages will be warranted with the inactivated virus vaccines; and what will be their final level of effectiveness and durability [33].

Live attenuated virus vaccines are based on whole viruses that have been modified and hence weakened. A single dosage can stimulate immune responses against a wide variety of viral proteins, without infecting the body with the disease. However, a mutation in live attenuated viral compounds could potentially reinstate their harmful potency; or they may have deleterious consequences in individuals with compromised immunity. Moreover, in light that Covid-19 is excreted in the feces, there is a risk of transmitting the attenuated viral compound to healthy individuals, and the potential of viral fusion with alternative wild-type Cov versions [34].

\section{Covid-19 Mutations}

Covid-19 represents a mutation with a higher contagion rate when juxtaposed against SARS-CoV. Covid-19 Spike (S) protein binds with the ACE2 receptor in a manner that is 10 times more secure and steadfast than the juncture formed between the SARS-CoV Spike (S) with the ACE2 receptor. This finding pertains to both the Covid-19 increased rate of viral infection and transmissibility, explaining the speed with which Covid-19 has spread globally [35]. Since it first appeared in Wuhan, Covid-19 has mutated from 614D to 614G, basically exchanging the amino acid Aspartate (D) with the amino acid Glycine (G) in the genome's 614 position [36]. Korber et al. (2020) looked at single amino acid changes in 28,576 sequences of the trimeric Spike (S) protein that included both the subdomain Spike 1 (S1), which mediates the binding with the ACE2 receptor, and the Spike 2 (S2) subdomain that accomplishes the membrane fusion, ultimately resulting in the release of viral contents into the cell. These investigators found that the Spike variant D614G that exchanges Aspartate with Glycine had a significantly higher rate of transmissibility globally, when compared to its predecessor 614D. Several countries were affected including Europe, the USA, Canada and Australia. This new mutation D614G varied only $0.3 \%$ from the original 614D Covid-19 sequence that was identified in Wuhan. Interestingly, this mutation that was solely based on a single substitution of the amino acid Aspartate (D) by the amino acid Glycine $(G)$ in Spike's $614^{\text {th }}$ amino acid position, resulted in an increase of at least $20 \%$ in the viral infectiousness rate [37]. While 614D only involves one conformation, D614G exhibits two to three Spike protein conformations, thus increasing the probability of contagion [38].

Covid-19 genome has undergone several mutations, usually based on one or two amino acid substitutions that reflect the virus' adaptation to each host's di- 
verse biological apparatus to maximize viral survival and transmissibility. Some of these changes may not be as important as others. Van Dorp et al. (2020) reported changes in the non-structural proteins Nsp6, Nsp11, Nsp13 as well as the trimeric spike [39]. However, if instead of the Nsp6, Nsp11 and Nsp13, the non-structural proteins Nsp7, Nsp8, and Nsp12 in association with Nsp14 were involved, the antigen's capacity to replicate long viral RNA would have been compromised. Research on previous versions of the antigen indicated that the mutation of the nsp8 residues P183 and R190 that are involved in the interphase between nsp8 and nsp12 as well as K58 had deleterious effects for the virus [40]. Figure 1 and Figure 2 illustrate that Covid-19 Non-structural protein (Nsp) transformations are adaptive allowing the virus to survive, in contrast to other coronavirus Nsp transformations that lead to the eventual extinction of the disease.

Another variant, the A222V that substitutes Alanine with Valine on the $222^{\text {nd }}$ position, was linked to Italy and Spain and appeared to represent about $11.2 \%$ of the genetic sequences collected from Covid-19 patients between June and October 2020. This mutant seemed to primarily affect immune recognition since it occurred in the S protein segment that binds with the ACE2 receptor [41] [42]. Overall D614G was manifested in around $86.5 \%$ of Covid-19 infections, while other mutants, such as the A222V, were relatively less frequent. D614G was often present along with $\mathrm{A} 222 \mathrm{~V}$, as well as other common mutations such as the S477N that exchanged Serine (S) with Asparagine (N) at the $477^{\text {th }}$ position and L5F. Several other mutations have been identified such as the L18F reflecting a Leucine (L) exchange with Phenylalanine (F), the A262S involving a switch between Alanine (A) and Serine (S), and other far less frequent ones such as the T632N (Threonine to Asparagine), V3G (Valine to Glycine), D574Y (Aspartate to Tyrosine), P272L (Proline to Leucine), D1163Y (Aspartate to Tyrosine), and others. The S protein contains around 98,699 amino acid sequencies, each consisting of around 1273 amino acid. Around 3205 of these amino acid sequences that compose the Spike protein are unique, suggesting that Covid-19 has evolved significantly, obtaining genetic diversity from previous versions of coronavirus [43].

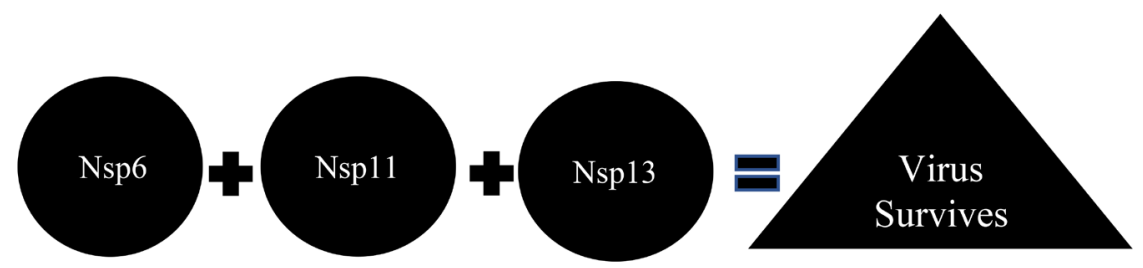

Figure 1. Covid-19 Nsp transformations are adaptive, leading to the survival of the virus.

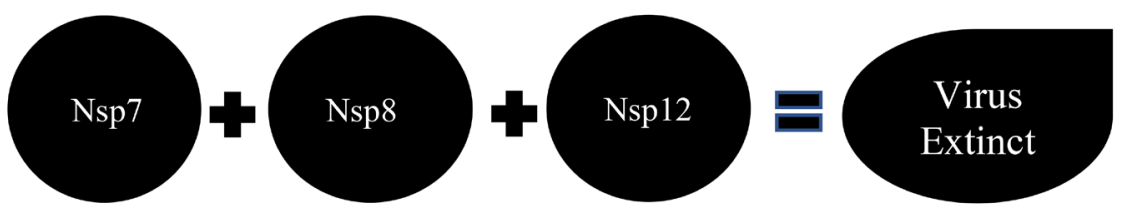

Figure 2. Coronaviruses (other than Covid-19) Nsp transformations may have deleterious effects for the virus leading to its extinction. 
Recently, a highly contagious new mutant, the B117 appeared in the UK in September 2020, currently accounting for around two thirds of the UK cases, only after three months. Since then it has already spread to around 24 USA states, and was recently identified in a few cases in Hong Kong. The B117 may have emerged as the virus multiplied within an infected immunocompromised patient, and it appears to be up to $70 \%$ more transmissible [44]. It combines around 23 mutants, primarily affecting the Spike protein, that include substitutions of amino acid Asparagine (N) with Tyrosine (Y) at the 501 position forming the mutant N501Y; amino acid Alanine (A) with Aspartate (D) at the 570 position, composing A570D; the D614G variant discussed above that involves replacement of Aspartate (D) with Glycine (G) at the 614 position; $P 681 \mathrm{H}$ entailing an interchange of Proline $(\mathrm{P})$ with Histidine $(\mathrm{H})$ at the 681 position; T716I reflecting a switch of Threonine (T) with Isoleucine (I) at the 716 position; the S982A featuring an exchange between Serine (S) and Alanine (A) at position 982; D1118H representing a commutation between Aspartate (D) with Histidine (H) at position 1118, etc [44]. Seventeen out of these 23 alterations appear to have occurred simultaneously, expressing a successful viral transformation with the purpose to disguise viral proteins compromising the antibodies' efficacy against the infection (see Figure 3).

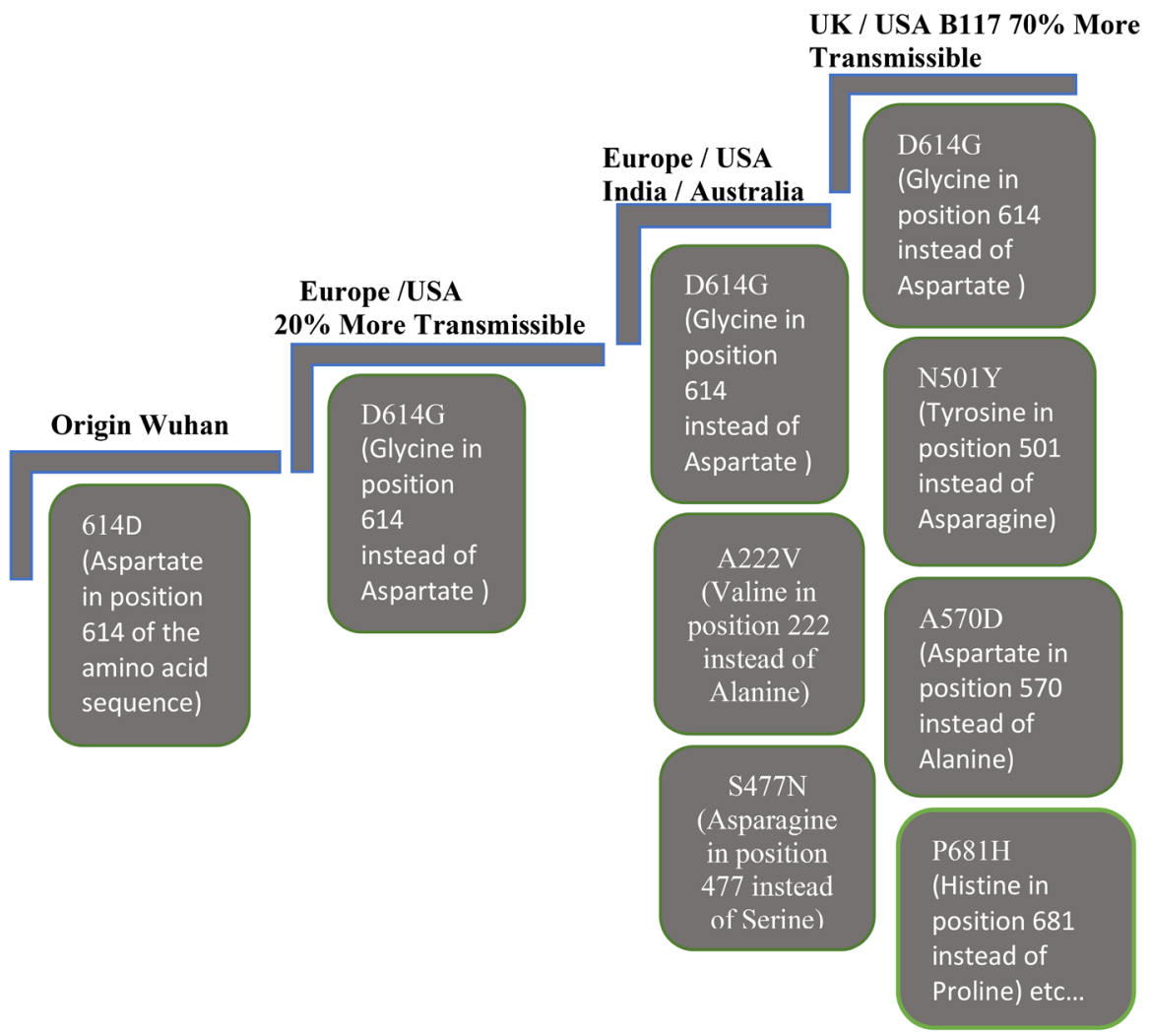

Figure 3. The Covid-19 evolution of transformations has significantly enhanced the Covid-19 transmissibility rate as demonstrated by the $70 \%$ more contagious B117 variant. This distinguishes Covid-19 from previous coronaviruses that became extinct as a result of repeated mutations. 
The mutation N501Y modifies the structure of the S protein camouflaging it from immune detection and threatening to eventually render ineffective all vaccines targeting the $\mathrm{S}$ protein. What is remarkable is that after undergoing around 300,000 mutations, Covid-19 mutants have evolved into being more effective and contagious rather than disintegrating into extinction, which is what would be expected if such accumulated mutations were random. As if there is some calculated intelligent programming within Covid-19 that renders mutations purposeful something that has never been encountered previously in naturally occurring coronaviruses [45] [46].

The 501.V2 variant which is at least as dangerously transmissible as the UK B117 has also been spreading globally. It is known to have three main substitutions of amino acid Lysine $(\mathrm{K})$ into Asparagine $(\mathrm{N})$ at the 417 position $(\mathrm{K} 417 \mathrm{~N})$; the variant $\mathrm{E} 484 \mathrm{~K}$ that involves Glutamate $(\mathrm{E})$ being switched into Lysine $(\mathrm{K})$ at position 484; and the mutant N501Y where Asparagine $(\mathrm{N})$ is replaced by Tyrosine $(\mathrm{Y})$ at the 501 position of the genetic sequence. The N501Y that is shared by both the B117 and the 501.V2 and which enhances the affinity between the Spike protein and the ACE2 receptor appears to be compromised by the K417N and E484K variants, possibly rendering the African mutation less infectious and effective than the British one. These two transformations' deleterious effects are based on the action of $\mathrm{E} 484 \mathrm{~K}$ and $\mathrm{K} 417 \mathrm{~N}$ resulting in disrupting the salt bridges developed by $\mathrm{E} 484$ and $\mathrm{K} 417$ after these two variants have been transformed into $484 \mathrm{~K}$ and $417 \mathrm{~N}$ that do not support salt bridges with BD23 R108/H11013 R52 and C105 E96/E99 respectively [47].

Additional highly contagious mutations like the 501Y.V2 or, as otherwise termed, B1351, that shares a lot of the variants composing B117, and the P1 from Brazil have recently emerged. The 501Y.V2 includes 19 mutations, with nine of them located in the Spike protein including the N501Y (Asparagine being replaced by Tyrosine), the E484K (Glutamate being replaced by Lysine) and K417N (Lysine being exchanged by Asparagine). It also lodges mutations on the N-terminal domain, including L18F-replacing Leucine (L) with Phenylalanine (F) in the $18^{\text {th }}$ position, D80A-transposing Aspartate (D) with Alanine (A) at the $80^{\text {th }}$ position, and $\mathrm{D} 215 \mathrm{~F}$ that substitutes Aspartate (D) by Phenylalanine (F) at the 215 position. The $\mathrm{P} 1$ mutation displays 17 unique amino acid reversals, four nucleotide insertions and four deletions. P1, B117 and 501Y.V2 all harbour the N501Y mutation that enhances the contact affinity between the Spike protein and the ACE2 receptor, rendering the variant significantly more contagious [48].

\section{Conclusion}

We traced the coronavirus classification and evolution, analysed the Covid-19 composition and its distinguishing characteristics when compared to SARS-CoV and MERS-CoV. Despite their close kinship, SARS-CoV and Covid-19 display significant structural differences, including 380 amino acid substitutions, and variable homology between certain open reading frames that are bound to diver- 
sify the pathogenesis and virulence of the two viral compounds. A single amino acid substitution such as replacing Aspartate (D) with Glycine (G) composes the D614G mutation that is around 20\% more infectious than its predecessor 614D. The $\mathrm{B} 117$ variant, that exhibits a $70 \%$ transmissibility rate, harbours 23 mutants, each reflecting one amino acid exchange. We examined several globally spreading mutations, 501.V2, B1351, P1, and others, with respect to the specific amino acid conversions involved. Unlike previous versions of coronavirus, where random mutations eventually precipitate extinction, the multiplicity of over 300,000 mutations appears to have rendered Covid-19 more contagious, facilitating its ability to evade detection, thus challenging the effectiveness of a large variety of emerging vaccines. Vaccination enhances immune memory and intelligence to combat or obstruct viral entry by generating antibodies that will prohibit the cellular binding and fusion with the Spike protein, ultimately debilitating the virus from releasing its contents into the cell. Developing antibodies during the innate response, appears to be the most compelling solution in light of the hypothesis that Covid-19 inhibits the production of Interferon type I, compromising adaptive efficiency to recognize the virus, possibly provoking a cytokine storm that injures vital organs. With respect to that perspective, the safety and effectiveness of different vaccines are evaluated and compared, including the Spike protein mRNA version, the Adenovirus DNA, Spike protein subunits, the deactivated virus genres, or, finally, the live attenuated coronavirus that appears to demonstrate the greatest effectiveness, yet, encompass a relatively higher risk.

\section{Conflicts of Interest}

The author declares no conflicts of interest regarding the publication of this paper.

\section{References}

[1] Li, F. (2016) Structure, Function, and Evolution of Coronavirus Spike Proteins. Annual Review of Virology, 3, 237-261. https://doi.org/10.1146/annurev-virology-110615-042301

[2] Decaro, N. and Lorusso, A. (2020) Novel Human Coronavirus (SARS-CoV-2): A Lesson from Animal Coronaviruses. Veterinary Microbiology, 244, Article ID: 108693. https://doi.org/10.1016/j.vetmic.2020.108693 http://www.sciencedirect.com/science/article/pii/S0378113520302935

[3] Schütze, H. (2016) Coronaviruses in Aquatic Organisms. In: Kibenge, F.S.B. and Godoy, M.G., Eds., Aquaculture Virology, Academic Press, Cambridge, 327-335. https://doi.org/10.1016/B978-0-12-801573-5.00020-6 https://www.sciencedirect.com/topics/agricultural-and-biological-sciences/deltacor onavirus

[4] Zhou, P., Yang, X.L., Wang, X.G., Hu, B., Zhang, L., Zhang, W., et al. (2020) Discovery of a Novel Coronavirus Associated with the Recent Pneumonia Outbreak in Humans and Its Potential Bat Origin. bioRxiv. https://doi.org/10.1101/2020.01.22.914952

[5] Surjit, M. and Lal, S.K. (2010) The Nucleocapsid Protein of the SARS Coronavirus: 
Structure, Function and Therapeutic Potential. In: Lal, S., Ed., Molecular Biology of the SARS-Coronavirus, Springer, Berlin, Heidelberg, 129-151. https://doi.org/10.1007/978-3-642-03683-5 9

[6] Wu, A., Peng, Y., Huang, B., Ding, X., Wang, X., Niu, P., et al. (2020) Genome Composition and Divergence of the Novel Coronavirus (2019-nCoV) Originating in China. Cell Host \& Microbe, 27, 325-328. https://doi.org/10.1016/j.chom.2020.02.001

[7] Ruan, Y.J., Wei, C.L., Ee, A.L., Vega, V.B., Thoreau, H., Su, S.T., et al. (2003) Comparative Full-Length Genome Sequence Analysis of 14 SARS Coronavirus Isolates and Common Mutations Associated with Putative Origins of Infection. Lancet, 361, 1779-1785. https://doi.org/10.1016/S0140-6736(03)13414-9

[8] Yang, Z.Y., Werner, H.C., Kong, W.P., Leung, K., Traggiai, E., Lanzavecchia, A. and Nabel, G.J. (2005) Evasion of Antibody Neutralization in Emerging Severe Acute Respiratory Syndrome Coronaviruses. Proceedings of the National Academy of Sciences of the United States of America, 102, 797-801. https://doi.org/10.1073/pnas.0409065102

[9] Grifoni, A., Sidney, J., Zhang, Y., Scheuermann, R.H., Peters, B. and Sette, A. (2020) A Sequence Homology and Bioinformatic Approach Can Predict Candidate Targets for Immune Responses to SARS-CoV-2. Cell Host Microbe, 27, 670-680.E2. https://doi.org/10.1016/j.chom.2020.03.002

[10] Wu, F., Zhao, S., Yu, B., Chen, Y.M., Wang, W., Song, Z.G., Zhang, Y.Z., et al. (2020) A New Coronavirus Associated with Human Respiratory Disease in China. Nature, 579, 265-269. https://doi.org/10.1038/s41586-020-2008-3

[11] Wrapp, D. and McLellan, J.S. (2019) The 3.1-Angstrom Cryo-Electron Microscopy Structure of the Porcine Epidemic Diarrhea Virus Spike Protein in the Prefusion Conformation. Journal of Virology, 93, e00923-19.

https://doi.org/10.1128/JVI.00923-19

[12] Chi, X., Yan, R., Zhang, J., Zhang, G., Zhang, Y., Hao, M., Zhang, Z., Fan, P., Dong, Y., Yang, Y. and Chen, Z. (2020) A Neutralizing Human Antibody Binds to the N-Terminal Domain of the Spike Protein of SARS-CoV-2. Science, 369, 650-655. https://doi.org/10.1126/science.abc6952

[13] Litman, G.W., Rast, J.P., Shamblott, M.J., Haire, R.N., Hulst, M., Roess, W., Litman, R.T., Hinds-Frey, K.R., Zilch, A. and Amemiya, C.T. (1993) Phylogenetic Diversification of Immunoglobulin Genes and the Antibody Repertoire. Molecular Biology and Evolution, 10, 60-72. https://doi.org/10.1093/oxfordjournals.molbev.a040000

[14] Wu, F., Wang, A., Liu, M., Wang, Q., Chen, J., Xia, S., et al. (2020) Neutralizing Antibody Responses to SARS-CoV-2 in a COVID-19 Recovered Patient Cohort and Their Implications. medRxiv, 2020-033020047365. https://dx.doi.org/10.2139/ssrn.3566211

[15] Lo, A.W., Tang, N.L. and To, K.F. (2006) How the SARS Coronavirus Causes Disease: Host or Organism? The Journal of Pathology, 208, 142-151. https://doi.org/10.1002/path.1897

[16] Chen, P., Nirula, A., Heller, B., Gottlieb, R.L., Boscia, J., Morris, J., et al. (2020) SARS-CoV-2 Neutralizing Antibody LY-CoV555 in Outpatients with Covid-19. New England Journal of Medicine, 384, 229-237. https://doi.org/10.1056/NEJMoa2029849

[17] Gaunt, E.R., Hardie, A., Claas, E.C., Simmonds, P. and Templeton, K.E. (2010) Epidemiology and Clinical Presentations of the Four Human Coronaviruses 229E, HKU1, NL63, and OC43 Detected over 3 Years Using a Novel Multiplex Real-Time 
PCR Method. Journal of Clinical Microbiology, 48, 2940-2947. https://doi.org/10.1128/JCM.00636-10

[18] Weiss, S.R. and Navas-Martin, S. (2005) Coronavirus Pathogenesis and the Emerging Pathogen Severe Acute Respiratory Syndrome Coronavirus. Microbiology and Molecular Biology Reviews, 69, 635-664. https://doi.org/10.1128/MMBR.69.4.635-664.2005

[19] Amanat, F., Stadlbauer, D., Strohmeier, S., Nguyen, T.H., Chromikova, V., McMahon, M., Jiang, K., Arunkumar, G.A., Jurczyszak, D., Polanco, J. and BermudezGonzalez, M. (2020) A Serological Assay to Detect SARS-CoV-2 Seroconversion in Humans. Nature Medicine, 26, 1033-1036. https://doi.org/10.1038/s41591-020-0913-5

[20] Tang, F., Quan, Y., Xin, Z.T., Wrammert, J., Ma, M.J., Lv, H., Wang, T.B., Yang, H., Richardus, J.H., Liu, W. and Cao, W.C. (2011) Lack of Peripheral Memory B Cell Responses in Recovered Patients with Severe Acute Respiratory Syndrome: A SixYear Follow-Up Study. The Journal of Immunology, 186, 7264-7268. https://doi.org/10.4049/jimmunol.0903490

[21] Wagner, A. and Weinberger, B. (2020) Vaccines to Prevent Infectious Diseases in the Older Population: Immunological Challenges and Future Perspectives. Frontiers in Immunology, 11, Article No. 717. https://doi.org/10.3389/fimmu.2020.00717

[22] Braun, J., Loyal, L., Frentsch, M., Wendisch, D., Georg, P., Kurth, F., et al. (2020) SARS-CoV-2-Reactive T Cells in Healthy Donors and Patients with COVID-19. Nature, 587, 270-274. https://doi.org/10.1038/s41586-020-2598-9

[23] Grifoni, A., Weiskopf, D., Ramirez, S.I., Mateus, J., Dan, J.M., Moderbacher, C.R., et al. (2020) Targets of T Cell Responses to SARS-CoV-2 Coronavirus in Humans with COVID-19 Disease and Unexposed Individuals. Cell, 181, 1489-1501.E15. https://doi.org/10.1016/j.cell.2020.05.015

[24] Prompetchara, E., Ketloy, C. and Palaga, T. (2020) Immune Responses in COVID19 and Potential Vaccines: Lessons Learned from SARS and MERS Epidemic. Asian Pacific Journal of Allergy and Immunology, 38, 1-9. http://apjai-journal.org/wp-content/uploads/2020/03/1.pdf?fbclid=IwAR1kVlFnoc6 mobqEy7FDz 93fX AaY8ZgE4TUwtjzhh8oVqgs82rgf3QoU

[25] Faure, E., Poissy, J., Goffard, A., Fournier, C., Kipnis, E., Titecat, M., et al. (2014) Distinct Immune Response in two MERS-CoV-Infected Patients: Can We Go from Bench to Bedside? PLOS ONE, 9, e88716. https://doi.org/10.1371/journal.pone.0088716

[26] Killerby, M.E., Biggs, H.M., Haynes, A., Dahl, R.M., Mustaquim, D., Gerber, S.I. and Watson, J.T. (2018) Human Coronavirus Circulation in the United States 20142017. Journal of Clinical Virology, 101, 52-56. https://doi.org/10.1016/j.jcv.2018.01.019

[27] Maruggi, G., Zhang, C., Li, J., Ulmer, J.B. and Yu, D. (2019) mRNA as a Transformative Technology for Vaccine Development to Control Infectious Diseases. Molecular Therapy, 27, 757-772. https://doi.org/10.1016/j.ymthe.2019.01.020

[28] Connors, M., Graham, B.S., Lane, H.C. and Fauci, A.S. (2021) SARS-CoV-2 Vaccines: Much Accomplished, Much to Learn. Annals of Internal Medicine. https://doi.org/10.7326/M21-0111

[29] Chen, W.H., Strych, U., Hotez, P.J. and Bottazzi, M.E. (2020) The SARS-CoV-2 Vaccine Pipeline: An Overview. Current Tropical Medicine Reports, 7, 61-64. https://doi.org/10.1007/s40475-020-00201-6

[30] Vartak, A. and Sucheck, S.J. (2016) Recent Advances in Subunit Vaccine Carriers. 
Vaccines, 4, 12. https://doi.org/10.3390/vaccines4020012

[31] Gao, Q., Bao, L., Mao, H., Wang, L., Xu, K., Yang, M., et al. (2020) Development of an Inactivated Vaccine Candidate for SARS-CoV-2. Science, 369, 77-81. https://doi.org/10.1126/science.abc1932

[32] Li, L., Guo, P., Zhang, X., Yu, Z., Zhang, W. and Sun, H. (2020) SARS-CoV-2 Vaccine Candidates in Rapid Development. Human Vaccines \& Immunotherapeutics, 1-10. https://doi.org/10.1080/21645515.2020.1804777

[33] Ng, W.H., Liu, X. and Mahalingam, S. (2020) Development of Vaccines for SARSCoV-2. F1000Research, 9. https://doi.org/10.12688/f1000research.25998.1

[34] Chen, Y. and Li, L. (2020) SARS-CoV-2: Virus Dynamics and Host Response. The Lancet Infectious Diseases, 20, 515-516. https://doi.org/10.1016/S1473-3099(20)30235-8

[35] Wrapp, D., Wang, N., Corbett, K.S., Goldsmith, J.A., Hsieh, C.L., Abiona, O., Graham, B.S. and McLellan, J.S. (2020) Cryo-EM Structure of the 2019-nCoV Spike in the Prefusion Conformation. Science, 367, 1260-1263.

https://doi.org/10.1126/science.abb2507

[36] Daniloski, Z., Jordan, T.X., Ilmain, J.K., Guo, X., Bhabha, G., tenOever, B.R. and Sanjana, N.E. (2020) The D614G Mutation in SARS-CoV-2 Spike Increases Transduction of Multiple Human Cell Types. bioRxiv.

https://doi.org/10.1101/2020.06.14.151357

[37] Korber, B., Fischer, W.M., Gnanakaran, S., Yoon, H., Theiler, J., Abfalterer, W., et al. (2020) Tracking Changes in SARS-CoV-2 Spike: Evidence That D614G Increases Infectivity of the COVID-19 Virus. Cell, 182, 812-827.E19. https://doi.org/10.1016/j.cell.2020.06.043

[38] Callaway, E. (2020) Making Sense of Coronavirus Mutations. Nature, 585, 174-177. https://search.bvsalud.org/global-literature-on-novel-coronavirus-2019-ncov/resour ce/en/covidwho- 752538

[39] van Dorp, L., Acman, M., Richard, D., Shaw, L.P., Ford, C.E., Ormond, L., et al. (2020) Emergence of Genomic Diversity and Recurrent Mutations in SARS-CoV-2. Infection, Genetics and Evolution, 83, Article ID: 104351. https://doi.org/10.1016/j.meegid.2020.104351

[40] Subissi, L., Posthuma, C.C., Collet, A., Zevenhoven-Dobbe, J.C., Gorbalenya, A.E., Decroly, E., Snijder, E.J., Canard, B. and Imbert, I. (2014) One Severe Acute Respiratory Syndrome Coronavirus Protein Complex Integrates Processive RNA Polymerase and Exonuclease Activities. Proceedings of the National Academy of Sciences, 111, E3900-E3909. https://doi.org/10.1073/pnas.1323705111

[41] Bartolini, B., Rueca, M., Gruber, C.E.M., Messina, F., Giombini, E., Ippolito, G., Capobianchi, M.R. and Di Caro, A. (2020) The Newly Introduced SARS-CoV-2 Variant A222V is Rapidly Spreading in Lazio Region, Italy. medRxiv. https://doi.org/10.1101/2020.11.28.20237016

[42] Zhang, B.Z., Hu, Y.F., Chen, L.L., Yau, T., Tong, Y.G., Hu, J.C., Cai, J.P., Chan, K.H., Dou, Y., Deng, J. and Wang, X.L. (2020) Mining of Epitopes on Spike Protein of SARS-CoV-2 from COVID-19 Patients. Cell Research, 30, 702-704. https://doi.org/10.1038/s41422-020-0366-X

[43] He, S. and Wong, S.W. (2021) Statistical Challenges in The analysis of Sequence and Structure Data for the COVID-19 Spike Protein. arXiv Preprint arXiv:2101.02304. https://arxiv.org/abs/2101.02304

[44] Duong, D. (2021) What's Important to Know about the New COVID-19 Variants? Canadian Medical Association Journal, 193, E141-E142. 
https://doi.org/10.1503/cmaj.1095915

[45] Liu, S., Shen, J., Fang, S., Li, K., Liu, J., Yang, L., Hu, C.D. and Wan, J. (2020) Genetic Spectrum and Distinct Evolution Patterns of SARS-CoV-2. Frontiers in Microbiology, 11, Article ID: 593548. https://doi.org/10.3389/fmicb.2020.593548

[46] Arif, T. (2021) The 501.V2 and B.1.1.7 Variants of Coronavirus Disease 2019 (COVID19): A New Time-Bomb in the Making? Infection Control \& Hospital Epidemiology, 1-2. https://doi.org/10.1017/ice.2020.1434

[47] Cheng, M.H., Krieger, J.M., Kaynak, B., Arditi, M.A. and Bahar, I. (2021) Impact of South African 501. V2 Variant on SARS-CoV-2 Spike Infectivity and Neutralization: A Structure-Based Computational Assessment. bioRxiv.

https://doi.org/10.1101/2021.01.10.426143

[48] Lopez-Rincon, A., Perez-Romero, C., Tonda, A., Mendoza-Maldonado, L., Claassen, E., Garssen, J. and Kraneveld, A.D. (2021) Design of Specific Primer Sets for the Detection of B. 1.1. 7, B. 1.351 and P. 1 SARS-CoV-2 Variants Using Deep Learning. bioRxiv. https://doi.org/10.1101/2021.01.20.427043 